\title{
Erratum to: Initiation and evolution of the South China Sea: an overview
}

\author{
Wei-dong Sun ${ }^{1,2}$ - Chiou-ting Lin ${ }^{1,3} \cdot$ Chan-chan Zhang ${ }^{1,3} \cdot$ Yong-bin $\mathrm{Hu}^{1,3}$. \\ Ming-xing Ling ${ }^{4} \cdot$ Xing Ding ${ }^{4} \cdot$ Cong-ying $\mathrm{Li}^{1} \cdot \mathrm{He} \mathrm{Li}^{1} \cdot \mathrm{Kai}^{\mathrm{Wu}}{ }^{1,3}$. \\ Wei-ming Fan $^{2}$
}

Published online: 16 June 2016

(c) Science Press, Institute of Geochemistry, CAS and Springer-Verlag Berlin Heidelberg 2016

\section{Erratum to: Acta Geochim (2016) DOI 10.1007/s11631-016-0110-x}

In the original publication, the article was published with some author names missing. The correct author names are provided in this erratum.

The online version of the original article can be found under doi:10.1007/s11631-016-0110-x.

Wei-dong Sun

weidongsun@gig.ac.cn

1 CAS Key Laboratory of Mineralogy and Metallogeny, Guangzhou Institute of Geochemistry, Chinese Academy of Sciences, Guangzhou 510640, People's Republic of China

2 CAS Center for Excellence in Tibetan Plateau Earth Sciences, Chinese Academy of Sciences, Beijing 100101, People's Republic of China

3 University of the Chinese Academy of Sciences, Beijing 100049, People's Republic of China

4 State Key Laboratory of Isotope Geochemistry, Guangzhou Institute of Geochemistry, Chinese Academy of Sciences, Beijing 510640, People's Republic of China 